\title{
Número de cromossomos em populações de Achyrocline satureioides Lam. (marcela) do Estado do Rio Grande do Sul, Brasil
}

\author{
Chromosome number in Achyrocline satureioides Lam. populations from Rio Grande do Sul State, Brazil
}

\author{
Liana Pereira de Pereira' ${ }^{1}$ Laura Patrícia da Luz ${ }^{1}$ Solange Bosio Tedesco² \\ Antonio Carlos Ferreira da Silva ${ }^{1}$
}

\begin{abstract}
A caracterização citogenética das plantas RESUMO medicinais de um país amplia as perspectivas da conservação da diversidade vegetal de espécies comumente utilizadas na medicina popular. Das espécies utilizadas medicinalmente no Brasil, algumas são nativas, dentre as quais se destaca, Achyrocline satureioides Lam. (marcela) da Família Asteraceae. Neste estudo, pela primeira vez, foi realizada a contagem do número cromossômico de populações de marcela, nativas do estado do Rio Grande do Sul. Foram coletadas sementes de cinco populações de marcela em seus locais de origem, as quais foram colocadas para germinar em ambiente controlado. Após a germinação, as pontas de raízes foram coletadas e prétratadas com paradiclorobenzeno durante cinco horas, fixadas em álcool absoluto:ácido acético glacial (3:1) por $24 \mathrm{~h}$ a temperatura ambiente $e$, posteriormente, conservadas em álcool 70\%, até o seu uso. A análise do número cromossômico foi feita a partir da confecção de lâminas das pontas das raízes, sendo que para o preparo das lâminas utilizou-se a técnica do esmagamento, hidrólise em $\mathrm{HCl} 5 \mathrm{~N}$ por 10min, aplicação de ácido acético 45\% durante $1 \mathrm{~min}$, esmagamento das pontas das raízes e coloração com orceína acética a $2 \%$. Todas as populações estudadas apresentaram $2 n=24$ cromossomos, o que sugere ser esse o número diplóide da espécie.
\end{abstract}

Palavras-chave: Achyrocline satureioides, cromossomos, plantas medicinais.

\section{ABSTRACT}

The cytogenetics of medicinal plants in a country enlarges the perspectives of conservation of the vegetal diversity of species generally used in popular medicine. Some of the species used medicinally in Brazil are native, and Achyrocline satureioides Lam. (marcela), from Asteraceae Family, is highlighted among them. In this study the first counting of the chromosomal number in marcela populations, which are native from Rio Grande do Sul State, was performed. Seeds of five populations of marcela were collected in their native local. Such seeds were put at room temperature to germinate. After germinating, the root-tips were collected and pre-treated with saturated solution of paradichlorobenzene for five hours, fixed in absolute ethanol glacial acetic acid (3:1) for 24 hours at room temperature and, after that, maintained in alcohol $70 \%$ until they were used. The analysis of the chromosomal number was performed with slides of root-tips by using the squashing technique, hydrolysis in HCI $5 \mathrm{~N}$ for $10 \mathrm{~min}$, acetic acid application $45 \%$ for $1 \mathrm{~min}$, squashing of the root-tips and staining in orcein acetic $2 \%$. All populations presented $2 n=24$ chromosomes, suggesting it as the probable diploid number of the species.

Key words: Achyrocline satureioides, chromosome, medicinal plants.

As plantas medicinais são muito utilizadas na medicina popular brasileira. No entanto, o seu uso indiscriminado e sem controle pode ser prejudicial à saúde humana. O potencial econômico de espécies medicinais nativas no Brasil é imenso, tanto que tais espécies são consideradas uma riqueza a ser preservada e utilizada, sendo necessário conservar a diversidade genética vegetal disponível. Para otimizar a utilização dos recursos medicinais nativos de um país, são indispensáveis estudos de caracterização do germoplasma de uma espécie e também propiciar que as mesmas sejam incluídas em um programa de melhoramento genético.

${ }^{1}$ Departamento de Biologia, Universidade Federal de Santa Maria (UFSM), Santa Maria, RS, Brasil.

${ }^{2}$ Departamento de Biologia, UFSM, Faixa de Camobi, Km 9, Campus Universitário, 97105-900, Santa Maria, RS, Brasil. stedesco@smail.ufsm.br. Autor para correspondência. 
Dentre as espécies medicinais, nativas do estado do Rio Grande do Sul, está Achyrocline satureioides (Fam. Asteraceae), popularmente conhecida por marcela, ou marcela-galega ou ainda marcela-da-terra (ALMEIDA, 1993). Achyrocline satureioides é uma uma erva anual, com ramos de até 1,5m de altura e com pilosidade branca, inflorescências amarelo-dourado do tipo capítulos, reunidas em panículas corimbosas (CASTRO \& CHEMALE, 1995). Seu centro de origem é a América Intertropical, ocorrendo naturalmente em todo o Brasil. É encontrada em todo o Rio Grande do Sul, e sua colheita ocorre entre março e abril, época em que os capítulos estão maduros (ALMEIDA, 1993). No Brasil, o chá das flores, folhas e ramos secos de marcela têm sido usados no tratamento de problemas gástricos, epilepsia e cólicas de origem nervosa. Além disso, a planta possui ação analgésica, antiespasmódica e sedativa (SIMÕES et al., 1989; LORENZI, 2000).

Esse trabalho foi desenvolvido para determinar o número cromossômico de populações nativas de Achyrocline satureioides ocorrentes no Rio Grande do Sul, já que não foram encontrados relatos na literatura a respeito de contagens do número de cromossomos dessa espécie. Os materiais pertencem ao banco de germoplasma de plantas medicinais do Jardim Botânico da Universidade Federal de Santa Maria (UFSM), Santa Maria, RS, Brasil, os quais fazem parte do projeto de caracterização de germoplasma de espécies medicinais brasileiras.

Foram coletadas sementes de cinco populações de marcela nativas do RS, listadas a seguir: População 1 (Silveira Martins/RS), População 2 (São Sepé/RS), População 3 (Santa Maria/Boca do Monte/ RS), População 4 (Camobi/RS287/ Santa Maria/RS), População 5 (Trevo Silveira Martins/Santa Maria/RS), região sul do Brasil. As amostras foram identificadas e depositadas no Herbário da UFSM. As sementes foram colocadas para germinar em meio ágar/água na concentração de $6,0 \mathrm{~g} \mathrm{~L}^{-1}$, no germinador com fotoperíodo de 12 horas de luz no laboratório de citogenética vegetal da UFSM.

Foi feita caracterização citogenética pela contagem do número cromossômico, utilizando-se pontas de raízes com 0,5 a $1 \mathrm{~cm}$ de comprimento, as quais foram coletadas e submetidas a pré-tratamento com paradiclorobenzeno. Esta metodologia foi utilizada por KLANT \& SCHIFINO-WITTMANN (2000) em leguminosas do gênero Lathyrus, exceto pelo tempo de exposição que foi de cinco horas. Em seguida, as raízes foram transferidas para o fixador álcool absolutoácido acético glacial (3:1) por 24 horas a temperatura ambiente e conservadas em álcool 70\% no refrigerador até o uso.
Foram feitas lâminas, preparadas por esmagamento (GUERRA \& SOUZA, 2002) para análise do número cromossômico. Para isto, pontas de raízes foram hidrolisadas em $\mathrm{HCl} 1 \mathrm{~N}$ por $5 \mathrm{~min}$, esmagadas em ácido acético $45 \%$ e coradas com orceína acética a $2 \%$. As lâminas com metáfases apropriadas para contagem, ou seja, aquelas em que as células apresentavam cromossomos espalhados e corados, as quais possilibitavam a contagem, foram analisadas. A contagem do número de cromosssomos foi realizada em aproximadamente 50 células de cada população e as lâminas que permitiram a contagem dos cromossomos foram transformadas em permanentes e fotografadas em fotomicroscópio com filme preto e branco, ASA 400.

Os dados obtidos para o número de cromossomos somáticos de Achyrocline satureioides mostraram que todas as células analisadas apresentaram 2n=24 cromossomos (Figura 1 Metáfases mitóticas de Achyrocline satureioides. acélula com 2n =2x =24 cromossomos da população Silveira Martins/RS, b- célula com 2n $=2 \mathrm{x}=24$ cromossomos da população São Sepé/RS, c- célula com $2 \mathrm{n}=2 \mathrm{x}=24$ cromossomos da população Santa Maria/ Boca do Monte/RS, d- célula com $2 \mathrm{n}=2 \mathrm{x}=24$ cromossomos da população Trevo Silveira Martins/ Santa Maria/RS). Percebe-se que, nessas populações estudadas de marcela houve problemas de espalhamento completo de seus cromossomos, dificultando o estudo, o que, no entanto, não impediu que fosse determinado o número exato de cromossomos dessa espécie. Argumenta-se que os cromossomos de marcela provavelmente possuem aderências que impedem o seu espalhamento total, ou novos protocolos devem ser testados.

Estudos sobre a contagem cromossômica em Achyrocline satureioides não foram encontrados na literatura até o momento. No entanto, trabalhos têm mostrado que para algumas espécies afro-americanas, distribuídas em regiões tropicais e subtropicais da América do Sul e Central, África e Madagascar, o número cromossômico básico foi relatado sendo $\mathrm{x}=7$, e registrado um complemento cromossômico haplóide $\mathrm{n}=14$, para Achyrocline alata (GIANGUALANI, 1976; AMAT, 1998); diferindo do encontrado para Achyrocline satureioides no presente trabalho $n=12$.

Estudos citogenéticos, conduzidos por HUNZIKER et al. (1989), foram realizados em vários gêneros da família Compositae, para determinar os números cromossômicos e comportamento meiótico de várias espécies, estando incluídas as plantas medicinais da família Asteraceae. Esses autores relataram para Solidago chilensis, a presença de nove cromossomos 


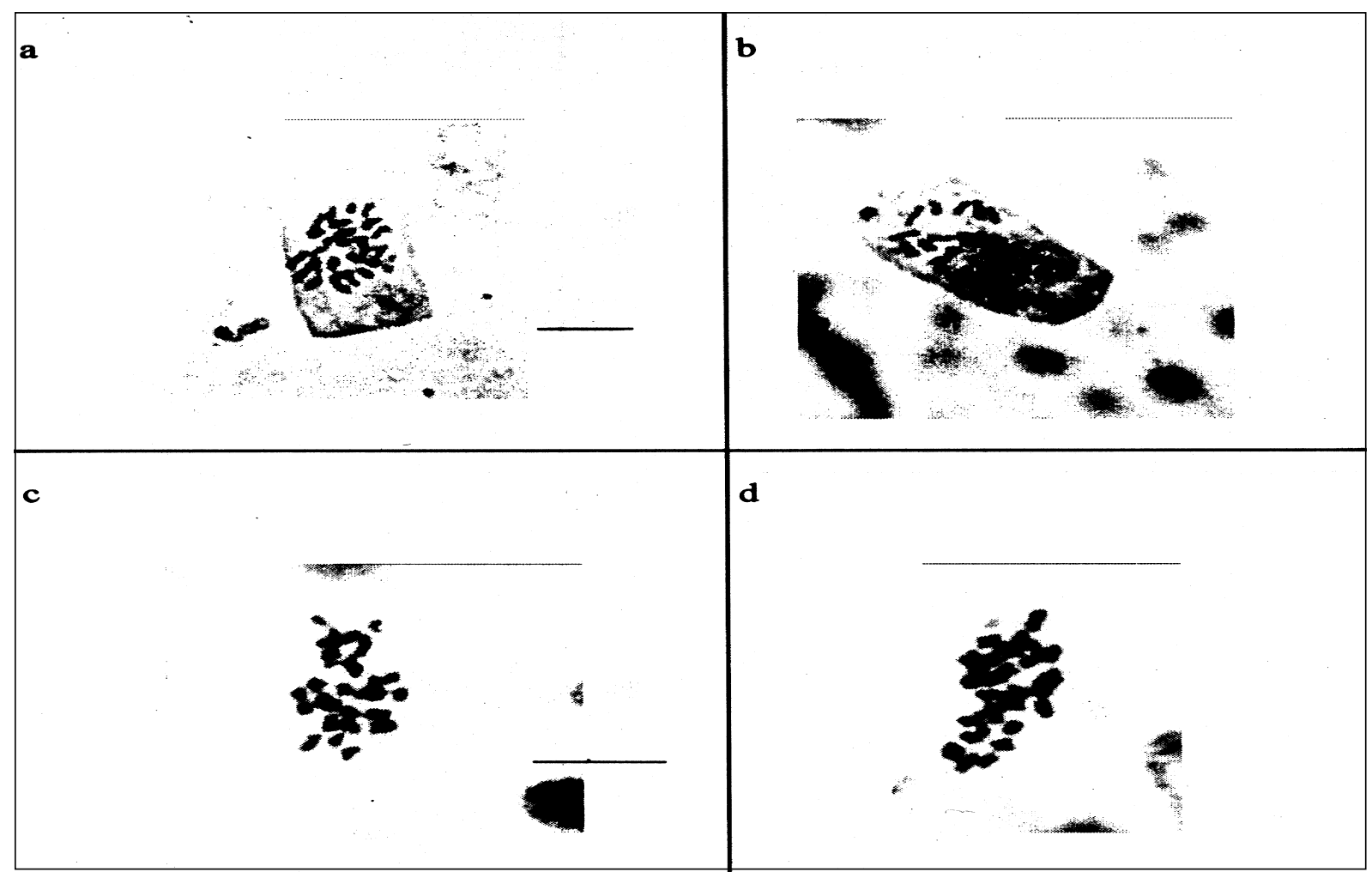

Figura 1 - metáfases mitóticas de Achyrocline satureioides. a- b- c- d células com 2n $=2 \mathrm{x}=24$ cromossomos das populações 1, 2, 3, e 4, respectivamente. Escala $=10 \mu \mathrm{m}$.

bivalentes em diacinese regular, sugerindo como número básico de cromossomos da espécie como $2 \mathrm{n}=18$, bem como o mesmo número para o gênero Bacharis. Na espécie Baccharis trimera (Less) DC. (carqueja), estudos de contagem cromossômica de AULER (2004), confirmaram o número de $2 n=2 x=18$ cromossomos para Bacharis trimera.

Aster squamatus (Spreng.), também da família Asteraceae, foi estudada por SOLBRIG et al. (1964), tendo $2 \mathrm{n}=2 \mathrm{x}=20$ cromossomos (diplóides), e determinado como número básico $\mathrm{x}=5$. Na espécie Mikania micrantha, foram relatadas contagens cromossômicas de $2 \mathrm{n}=2 \mathrm{x}=36$ e $2 \mathrm{n}=4 \mathrm{x}=72$ cromossomos, por MAFFEI et al. (1999).

Além desses, destaca-se estudo de LUNARDI et al. (2004), sobre a variabilidade no número cromossômico da planta medicinal Maytenus ilicifolia (espinheira-santa), onde ocorreram n=32, $n=35$ e $n=40$ cromosssomos, mostrando claramente existência de variabilidade intraespecífica entre as diferentes populações.

É relevante, através do exposto, ressaltar que existem lacunas a serem preenchidas, no que diz respeito aos estudos citogenéticos das plantas medicinais do RS, sendo que novas contribuições podem a longo prazo aumentar a eficácia das estratégias de conservação do germoplasma nativo, bem como realizar melhoramento genético das espécies medicinais de interesse comercial.

No presente trabalho, o número de cromossomos das cinco populações de Achyrocline satureioides está estabelecido como $2 n=2 x=24$ cromossomos, o que até o momento refere-se ao número diplóide dessa espécie, sugerindo-se como número básico $\mathrm{x}=12$ cromossomos.

\section{REFERÊNCIAS}

AMAT, A.G. El uso de caracteres hisfoliares em la identificación de las especies argentinas de genero Achyrocline D. C. (Asteraceae). Acta Framaceutica Bonaerense, v.7, n.2, p.7583, 1998.

ALMEIDA, E.R. Plantas medicinais brasileiras, conhecimentos populares e científicos. São Paulo: Hemus, 1993. 341p.

AULER, N.M.F. Distribuição da variabilidade genética em populações naturais de Bacharis trimera (Less) DC. (carqueja) no Sul do Brasil. 2004. 108f. Tese (Doutorado

Ciência Rural, v.36, n.2, mar-abr, 2006. 
em Agronomia)- Curso de Pós-graduação em Agronomia, Universidade Federal de Santa Maria.

CASTRO, L.O.; CHEMALE, V.M. Manual de identificação e cultivo de plantas medicinais, condimentares e aromáticas. Porto Alegre: Instituto de Pesquisas Agronômicas, 1995. 78p.

GIANGUALANI, R.N. Las espécies argentinas del gênero Achyrocline (Compositae). Darwiniana, v.20, n.3-4, p.549576, 1976.

GUERRA, M., SOUZA, M.J. Como observar cromossomos: um guia de técnicas em citogenética em citogenética vegetal, animal e humana. Ribeirão Preto: FUNPEC, 2002. 191p.

HUNZIKER, J.H. et al. Estudos cariologicos en compositae V. Darwiniana, v.29, n.1-4, p.25-39, 1989.

KLANT, A., SCHIFINO-WITTMANN, M.T. Karyotype morphology and evolution in some Lathyrus (Fabaceae) species of Southern Brazil. Genetics and Molecular Biology, v.23, n.2, p.463-467, 2000 .

LORENZI, H. Plantas daninhas do Brasil - terrestres, aquáticas, parasitas e tóxicas. Nova Odessa, SP: Instituto Plantarum, 2000. 640p.

LUNARDI, M.P.M. et al. Chromosome number variability in the south american medicinal plant Maytenus ilicifolia Mart. ex Reiss (Celastraceae). Cytologia, v.4, p.439-445, 2004.

MAFFEI, E.M.D. et al. Chromosomal polymorphism in 12 populations of Mikania micrantha (Compositae). Genetics and Molecular Biology, São Paulo, v.22, n.3, p.433-444, 1999.

SIMÕES, C.M. et al. Pharmacological Investigations on. Achyrocline satureioides (Lam.) DC., Compositae. Journal Ethanopharmacol, v.22, n.3, p.281-293, 1989.

SOLBRIG, O.T. et al. Chromosome numbers in Compositae V. Asterae II. Amer J Bot, v.51, p.513-519, 1964. 